\title{
ECOLOGICAL ECONOMICS FOR ENERGY CONSERVATION AND EMISSION REDUCTION OF HIGH ENERGY CONSUMING INDUSTRIES BASED ON THEORY OF CIRCULAR ECONOMY
}

\author{
LI, X. L. ${ }^{1 *}-$ YANG, C. Z. ${ }^{2}$ \\ ${ }^{1}$ School of Civil Engineering, Qinghai University, Xining 810016, China \\ ${ }^{2}$ Qinghai Provincial Institute of Geography and National Situation Monitoring, Xining 810001, \\ China \\ (phone: +86-133-8329-3867) \\ *Corresponding author \\ e-mail: lxlsource@163.com; phone: +86-136-1371-1818
}

(Received $7^{\text {th }}$ Jun 2019; accepted $10^{\text {th }}$ Oct 2019)

\begin{abstract}
The high energy consumption and the large amount of pollutants discharged by high-energyconsuming industries in the production process have posed a great threat to the ecological environment. This paper takes the theory of circular economy and the basic concept of sustainable development as the research foundation to study energy conservation, emission reduction and eco-economic construction of high-energyconsuming industries; and then it proposes countermeasures and suggestions for the ecological construction and development of such industries. The research shows that the reduction of energy consumption has contributed a lot to the reduction in the total energy consumption and the comparable energy consumption; In recent years, the energy consumption per one ton of steel has been decreasing year by year, and the energy conservation and emission reduction measures such as technological reform, policy regulation and economic coordination have played a major role in it; the energy-conservation and emission-reduction ecoeconomic system based on circular economy can mitigate improve the high energy consumption of the industries, which has laid a foundation for their ecological development. This paper has provided theoretical support and guidance for the energy conservation, emission reduction and the eco-economic construction of high-energy-consuming industries.
\end{abstract}

Keywords: circular economy, high energy-consuming industry, ecological economy, energy conservation and emission reduction, analytic hierarchy process

\section{Introduction}

Protection of the global environment, energy conservation and emission reduction, and the concept of sustainable development have become development strategies for industries around the globe (Price et al., 2011; Tu and Ma, 2018; Krishna, 2018; Liao, 2011). In recent years, the rapid development of the world economy, resources and industries has damaged to the environment. In order to build an environment-friendly and resource-saving society, countries have implemented energy conservation, emission reduction and the development of circular economy into the economic construction, in the hopes of maintaining the balance of environment and ecology, and controlling the severe pollution and high energy consumption in industrial development, thus improving the utilization of resources around the globe and building an ecological society (Lei et al., 2009; Tao et al., 2014; Cheng et al., 2012). In recent years, the demand for oil and coal resources has increased year by year, and the domestic resource supply cannot meet the demand in actual economic development (Algaba et al., 2012; Habib et al., 2016). In addition, at present, China's energy utilization rate is not high, and our mining and utilizing technology is not mature enough, which has caused 
adverse effects on the environment to a certain extent in the process of resource exploitation. Therefore, the research and practice of energy conservation, emission reduction and ecological development of high-energy-consuming industries is one of the main issues to be solved urgently.

Among various industries, the metallurgical industry is one of the industrial types that have high energy consumption and high pollutant emissions (Danza et al., 2018; Mostafaei et al., 2019; Trica et al., 2019; Jonas et al., 2018; Hobson and Lynch, 2016; Rudra and Chakraborty, 2017). The energy consumption in steelmaking and other metal smelting processes accounts for nearly a quarter of the total industrial energy consumption (Murray et al., 2017; Cordova-Pizarro et al., 2019; Rigueiro-Rodríguez et al., 2018). Although the country's energy consumption control policies and administrative measures have improved the problem of energy consumption and pollution emission to some extent, the efforts on energy conservation and emission reduction still unable to catch up with the control level in the developed countries. And the main reasons for the unsatisfactory control effects include: low energy utilization rate, inadequate control of pollutant emissions, low level of waste recycling technology, and lacking of effective control measures (Tiening and Jimei, 2018; Gallagher et al., 2017; Peters et al., 2007; Tomi and Schneider, 2017).

Based on the above-mentioned issues, the theory of circular economy and the basic concept of sustainable development, this paper starts from the perspective of energy conservation and emission reduction of metallurgical industry, and combines the development characteristics and overall trend of today's high energy-consuming industries to study the energy conservation, emission reduction and the ecological and economic construction of high-energy-consuming industries, and proposes countermeasures and suggestions for the ecological construction and development of high-energy-consuming industries, in the hopes of providing theoretical support for the energy conservation, emission reduction and the ecological and economic construction and development of high-energy-consuming industries.

\section{Materials and methods (related theories of circular economy)}

\section{Circular economy theories}

In the development of traditional economic, production activities such as ecological resource development, energy utilization, agricultural and industrial production, and waste generation have produced serious damages and environmental pollutions to our ecological environment. In today's society, environmental problems are becoming increasingly prominent, and countries around the world are gradually realizing that only by optimizing the economic development mode can we achieve coordinated construction and sustainable development of environment and social economy. In such social context, circular economy emerges as a new type of economic development mode.

The emergence of circular economy has alleviated or eliminated the conflicts and contradictions between environment and economic and social development to a certain extent, and realized the harmonious coexistence of the natural environment and human beings. The concept of circular economy refers to transform the traditional economic mode into an economic mode with resource recycling and energy conservation as the development goals within a complex system of nature, human, and technological development. The circular economy mode is a process of value re-creating, economy 
developing and environment coordinating with minimizing input costs and achieving maximal economic and environmental benefits through high resource utilization rate and low emission of exhaust pollutants as the goals.

In order to realize the ecological construction and development of the economy, the economic mode follows three principles: resource reduction, that is, reduce resource consumption, waste generation and reducing environmental damages during the production process; product recycling, that is, re-cycle and re-use the products, renovate or remould the old products and re-use them, so as to prolong the life cycle of the products; waste recycling, that is, convert the wastes generated during production into resources as much as possible with the highest conversion rate, thereby reducing consumption of natural resources and energy.

\section{Basic concepts of energy conservation and emission reduction}

Speaking from a micro level, the concept of energy conservation and emission reduction is to save energy and reduce pollutant emissions; while speaking from a macro level, this concept refers to save natural resources and energy sources, and reduce harmful substances and pollutant emissions. Studies have shown that the economic development process needs to be able to meet the requirements of humans and kept within a bearable range of the environment. If the regeneration ability of the nature and the self-coordination ability of the environment are destroyed during the development process, it will cause extremely serious ecological problems, and the social economy could not develop effectively and sustainably

The proposal of energy conservation and emission reduction stems from the problems of environmental degradation and resource crisis emerged from the traditional economic development mode, so countries around the globe have begun to adopt energy conservation and emission reduction measures. The above problems and the motivations for energy conservation and emission reduction can be attributed to the following reasons: the needs of human survival and social development, the decrease of nonrenewable resources, the deterioration of ecological environment and the requirements of sustainable social development. Therefore, environmental and energy issues are not only problems for the development of human beings, but also the premise for human to live in harmony with the nature.

\section{Development of high energy-consuming industries}

In recent years, high-energy-consuming industries such as the metallurgical industry are developing gradually, and the entire production processes (mining, smelting, processing, molding, etc.) consume a large amount of energy and discharge a large amount of wastes. The manufacturing procedures of steelmaking and the generated wastes are shown in Figure 1.

Due to the nature of the data in this paper, the complexity and cumbersomeness of the data such as the steel industry's energy consumption and types, this paper obtained some data from the public agency management department and the China Iron and Steel Association (CISA). Then, based on the statistical data of the CISA, further analysis was performed to achieve the development trends and internal laws. In addition, a combination of literature survey and data report analysis was applied in this study to summarize the data analyzed below for enhancing the use value and statistical significance of the data. 


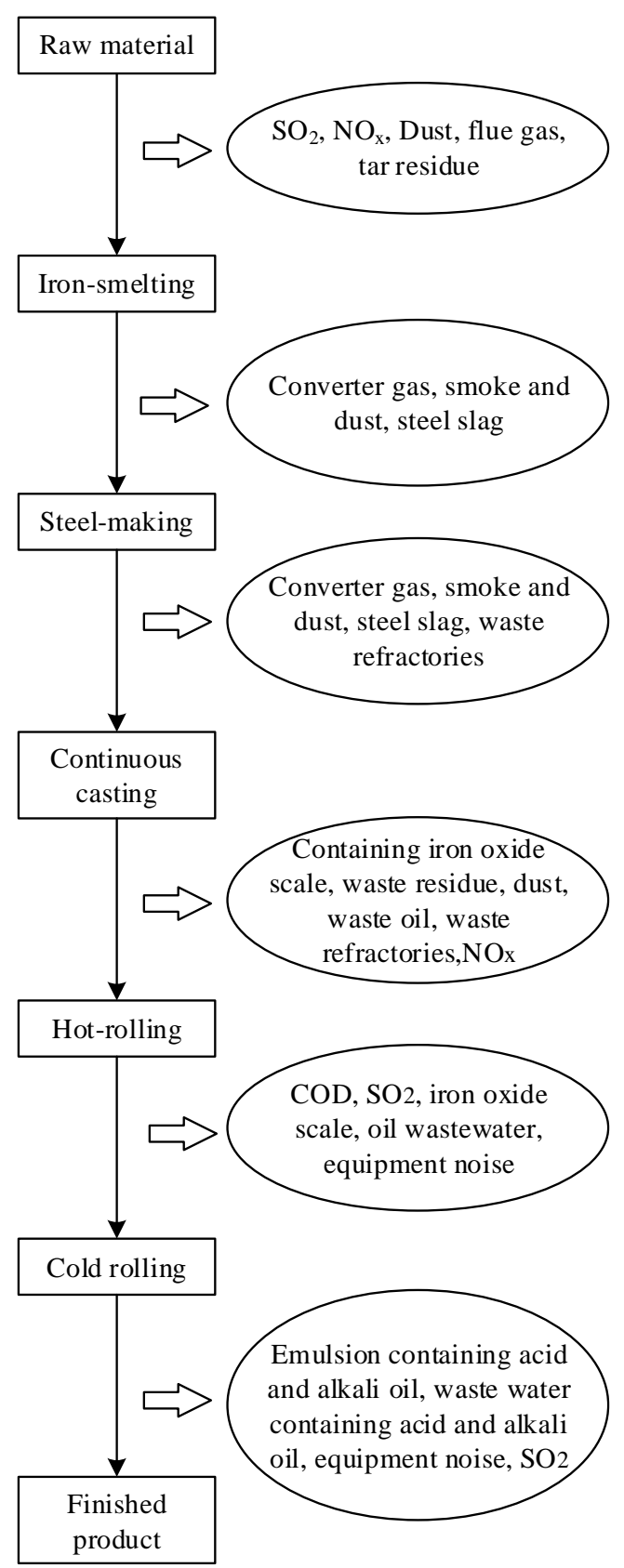

Figure 1. Manufacturing procedures of steelmaking and the generated wastes

According to the survey results obtained from public agency management and CISA, the energy consumption of major steelmaking companies in 2016 and 2017 is counted and shown in Table 1, and the statistical results are shown in Figure 2. Compared with the energy consumption in 2016, the energy consumption of the steelmaking industry decreased by about 3\%, and the electricity and water consumption of per ton steel production had been significantly reduced, which had brought great benefits to the economic development and energy-saving of the companies. In addition, the reduction in energy consumption of the manufacturing procedures has made great contributions to the reduction of total energy consumption and comparable energy consumption in steelmaking. 
Table 1. Energy consumption in steelmaking industry (kgce/t)

\begin{tabular}{c|c|c|c|c|c|c|c|c}
\hline & $\begin{array}{c}\text { Energy } \\
\text { consumption }\end{array}$ & Sinter & Pelletizing & Coking & Furnace & $\begin{array}{c}\text { Steel } \\
\text { rolling }\end{array}$ & $\begin{array}{c}\text { Power consumption } \\
(\mathbf{k W h} / \mathbf{t})\end{array}$ & $\begin{array}{c}\text { Water consumption } \\
\left(\mathbf{m}^{3} / \mathbf{t}\right)\end{array}$ \\
\hline 2016 & 668.7 & 48.6 & 27.1 & 98.5 & 434.7 & 59.8 & 451.4 & 3.12 \\
2017 & 648.4 & 46.8 & 25.4 & 94.8 & 425.1 & 56.3 & 438.9 & 3.09 \\
Reduction & 20.3 & 1.8 & 1.7 & 3.7 & 9.6 & 3.5 & 12.5 & 0.03 \\
Reduction rate (\%) & 3.04 & 3.70 & 6.27 & 3.76 & 2.21 & 5.85 & 2.77 & 0.96 \\
\hline
\end{tabular}

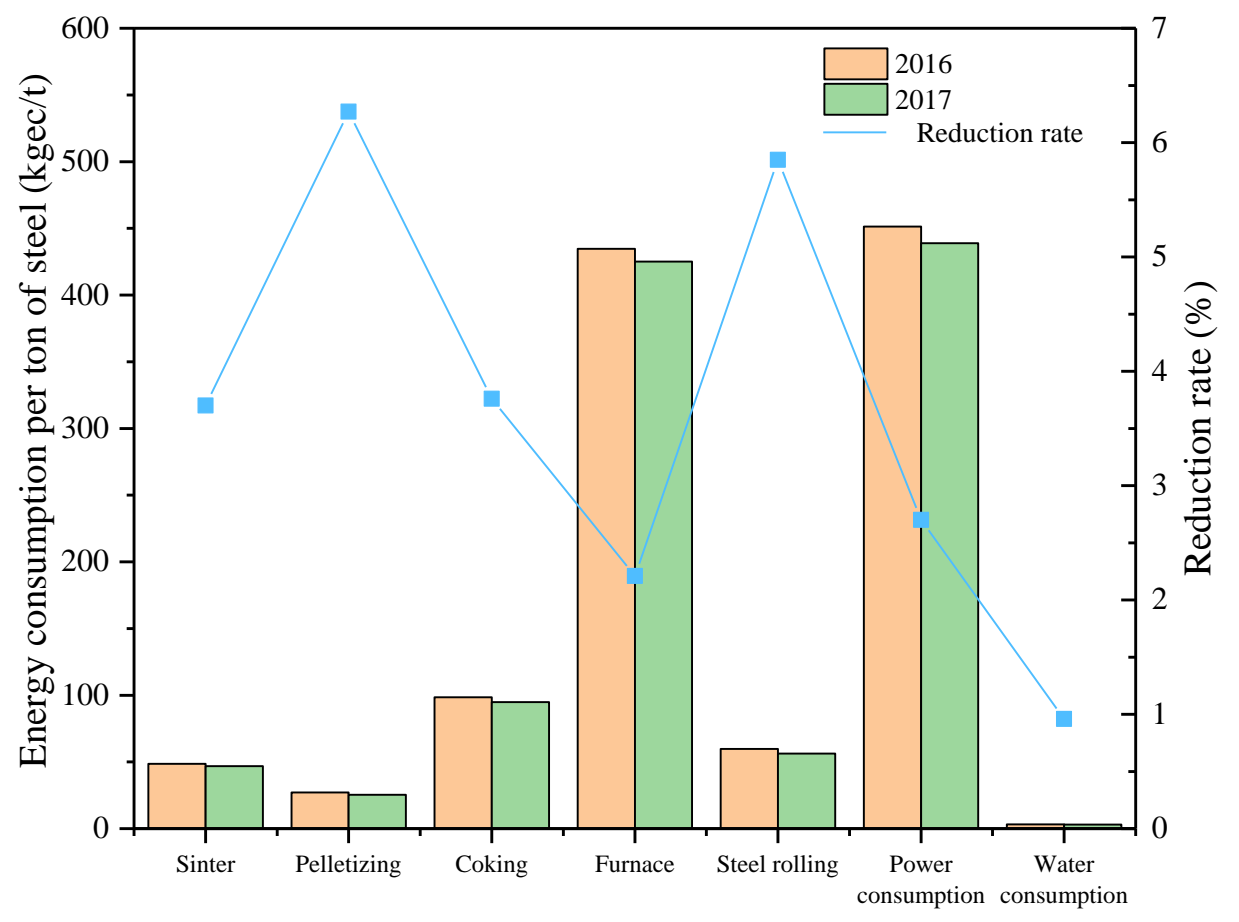

Figure 2. Energy consumption of per ton steel in each process (kgce/t)

In the past 7 years, the change trend of energy consumption of per ton steel production of major steelmaking companies is shown as Figure 3. It can be seen that the energy consumption of per ton steel production is decreasing year by year, indicating that the processing technologies of the metallurgic industry has made new progress, which is closely related to the policy control of energy conservation and emission reduction of high-energy-consuming industries and the develop of technology. However, from the perspective of circular economy, steel production still consumes a lot of energy, so the strategy of energy conservation and emission reduction still needs to be further implemented.

The CISA provides the data about the energy consumption per ton of steel in key steel industries in the past seven years. It can be seen from Figure 3 that the comprehensive energy consumption and comparable energy consumption of the per ton steel produced by the metallurgical industry are decreasing year by year, indicating that the technology of the steel enterprises is improving continuously, and the energy consumption of each process is also reduced to varying degrees, which has provided support for the reduction of comprehensive energy consumption and the emission of the 
waste. However, the energy consumption of these enterprises is still at a high level worldwide, and there is still room for improvement. If such enterprises can combine multiple aspects such as economy, government policy and technology to carry out the improvement, they will be able to realize further-level energy conservation and emission reduction, and build an ecological economy.

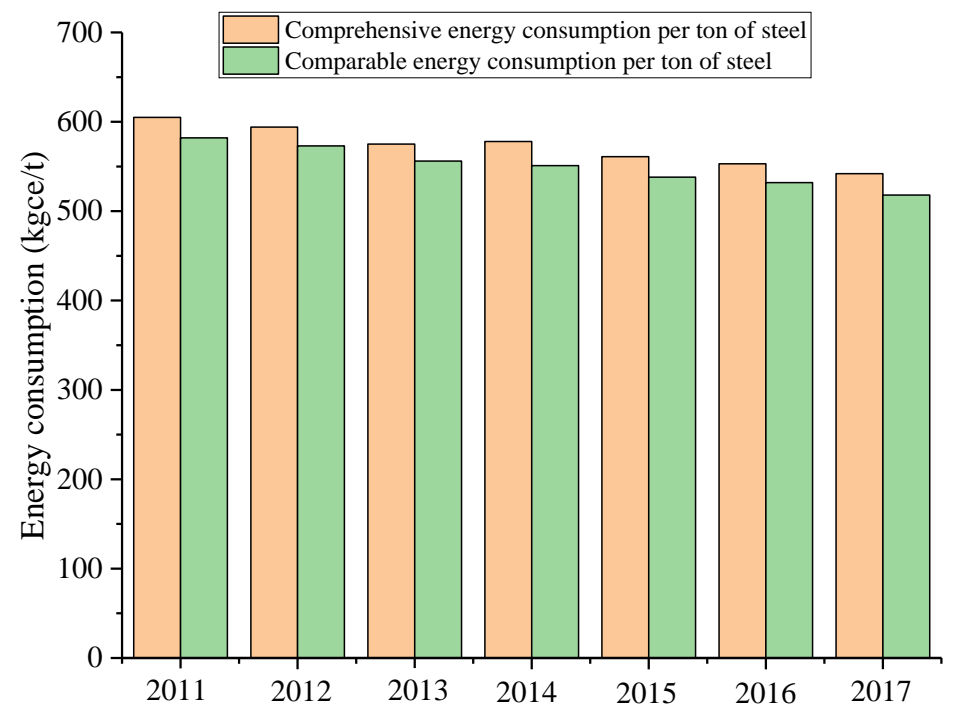

Figure 3. Changes in energy consumption of per ton steel in steelmaking companies

At present, in order to further implement energy conservation, emission reduction and develop ecological economy, the high-energy-consuming industries represented by the metallurgical industry have gradually transformed from economic benefit-oriented companies to harmonious enterprises, constantly rethinking the relationship between economic development, ecological environment and resources; in addition, these highenergy-consuming enterprises have also changed the traditional extensive management, and gradually improved to intensive management, thereby improving their unit output, and increasing social and economic benefits by optimizing resource allocation and elements of various links.

\section{Results (eco-economics of high energy-consuming industries)}

\section{Construction of energy conservation and emission reduction system}

The development of high-energy-consuming industries such as the metallurgical industry consumes a large amount of energy and resources. Therefore, based on the basic theory and principle of circular economy, we should adopt a comprehensive approach combining economy, policy and laws to implement energy conservation and emission reduction, and systematically build a comprehensive energy-saving and emission-reducing system. Therefore, based on the basic mechanism of energy conservation and emission reduction, combining with relevant theories of circular economy, this paper proposes the Best management Practices (BMP) comprehensive system for the energy conservation and emission reduction of high-energy-consuming industries, the basic processes are shown in Figure 4. Based on information platform, 
human resources and management, it adopts policy incentives, index constraints, target assessment and other approaches to guarantee the implementation, thereby achieving the goal of energy conservation and emission reduction of high-energy-consuming enterprises.

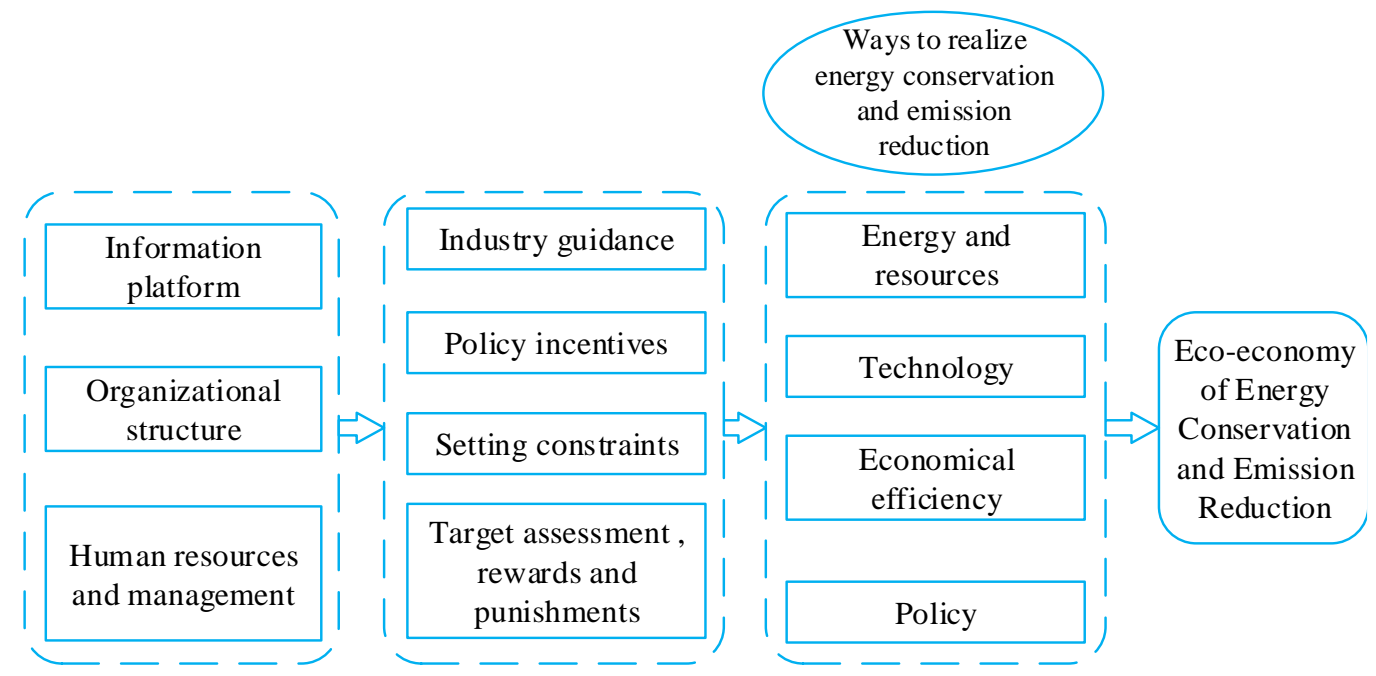

Figure 4. Energy conservation and emission reduction system

\section{Structure of energy conservation and emission reduction system}

When building the energy-conservation emission-reduction system, the construction of the system is guaranteed from three aspects: information platform, organizational structure and human resources. The information platform for energy conservation and emission reduction can integrate informationization and industrialization in depth, through information collection, processing, analysis and sharing of the energy conservation and emission reduction and the whole production process of the highenergy-consuming enterprises, it conducts dynamic monitoring and optimization processing on the whole production process, resource utilization, allocation of equipment and materials, and the condition of energy consumption, balances the economic benefits and energy, and finally achieves industrialized energy conservation and emission reduction. The management of the organizational structure is a comprehensive management system with government policies and regulations as guidance, production enterprises as subjects, and public and third parties as supervisors. The first is the government's guidance and control of the companies' production, energy conservation and emission reduction according to laws, regulations, and relevant economic policies, while within the companies, through hierarchical management and internal strategies, assessment system and reward and punishment policies for energy conservation and emission reduction are set up, and relevant liability system are established, so as to ensure the realization of the goal of energy conservation and emission reduction. And the human resources are to enable enterprises to cultivate professional and compound talents for energy conservation and emission reduction, learn the related theoretical knowledge of energy conservation and emission reduction and apply it to the actual production. The operation mechanism of the energyconservation emission-reduction system is shown in Figure 5, mainly including fiscal policies, rewards and punishments, and taxation policies. 


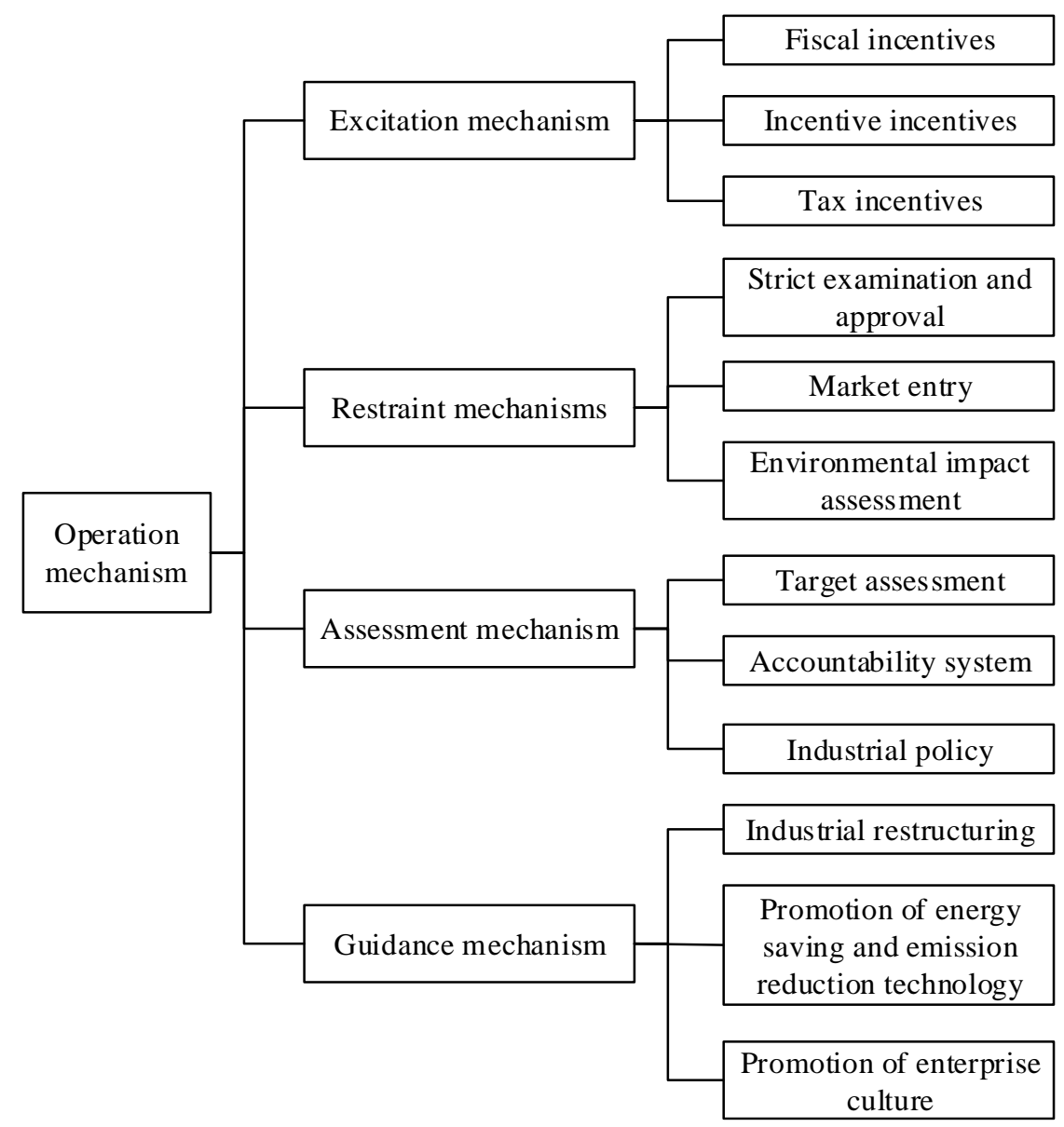

Figure 5. Operation mechanism of energy conservation and emission reduction system

\section{Discussion (analytic hierarchy process (AHP) of energy conservation and emission reduction)}

This paper first adopted the AHP to decompose the problem, as shown in Figure 6, the problem of circular economy development and energy conservation and emission reduction of high energy-consuming industries was divided into four layers (target layer, standard layer, index layer and scheme layer). The corresponding judgment matrix established is shown in Table 2. For the judgment matrix results, the value assignment was made according to the importance of factors, as shown in Table 3.

Based on the above judgment matrix, the relative weights of the elements were calculated using the sum method. For the inconsistent judgment matrix, the weights of the vectors in each column were calculated according to Equation 1, as for the consistent judgment matrix, after normalizing the vectors in each column, the corresponding weights could be obtained.

$$
W_{i}=\frac{1}{n} \sum_{j=1}^{n} \frac{a_{i j}}{\sum_{k=1}^{n} a_{k i}}
$$

After the relative weights of the elements were calculated, the consistency of the judgment matrix was tested, and the specific steps are as follows: calculate the 
consistency indicator C.I. according to Equation 2, and determine the average random consistency indicator R.I. according to Table 4; then according to Equation 3, use the consistency indicator and the average random consistency indicator to calculate the consistency ratio C.R., thereby determining the consistency of the judgment matrix. When the value of C.R. is less than 0.1, the judgment matrix is considered to be consistent; otherwise, it is inconsistent and needs to be modified.

$$
\begin{gathered}
C . I .=\frac{\lambda_{\max }-n}{n-1} \\
\text { C.R. }=\frac{\text { C.I. }}{\text { R.I. }}
\end{gathered}
$$

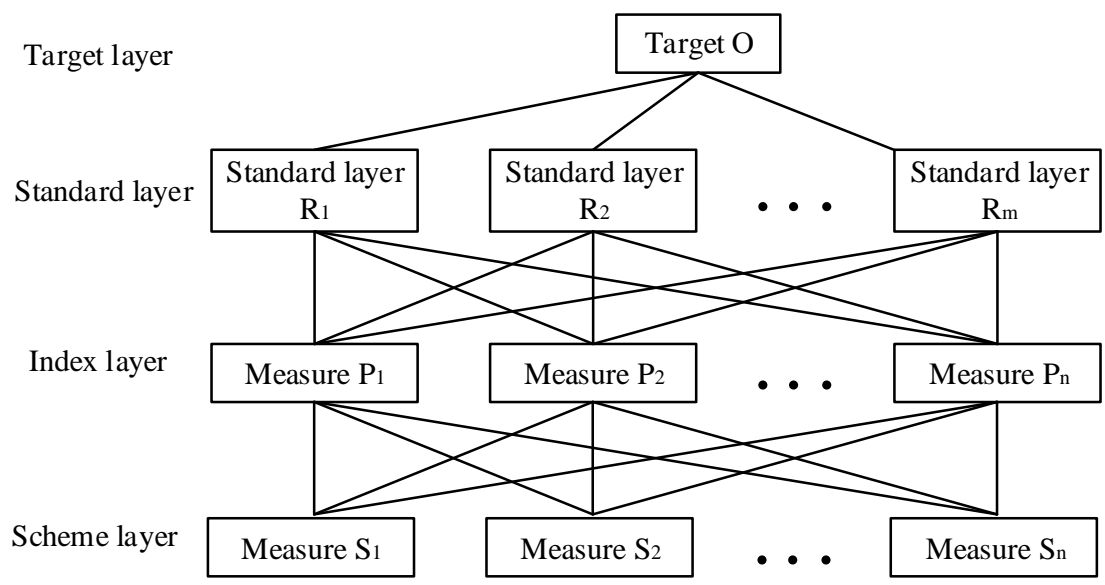

Figure 6. Model structure of analytic hierarchy process for green economy development

Table 2. The judgement matrix of green economy development level

\begin{tabular}{l|l|l|l|l}
\hline $\mathbf{M}_{\boldsymbol{x}}$ & $\mathbf{N}_{\mathbf{1}}$ & $\mathbf{N}_{\mathbf{2}}$ & $\mathbf{N}_{\mathbf{3}}$ & $\mathbf{N}_{\mathbf{4}}$ \\
\hline $\mathrm{N}_{1}$ & $\mathrm{n}_{11}$ & $\mathrm{n}_{12}$ & $\mathrm{n}_{13}$ & $\mathrm{n}_{14}$ \\
$\mathrm{~N}_{2}$ & $\mathrm{n}_{21}$ & $\mathrm{n}_{22}$ & $\mathrm{n}_{23}$ & $\mathrm{n}_{24}$ \\
$\mathrm{~N}_{3}$ & $\mathrm{n}_{31}$ & $\mathrm{n}_{32}$ & $\mathrm{n}_{33}$ & $\mathrm{n}_{34}$ \\
$\mathrm{~N}_{4}$ & $\mathrm{n}_{41}$ & $\mathrm{n}_{42}$ & $\mathrm{n}_{43}$ & $\mathrm{n}_{44}$ \\
\hline
\end{tabular}

\begin{tabular}{|c|c|}
\hline Assignment scale & Implication \\
\hline 1 & The two elements are equally important \\
\hline 3 & The former is slightly more important than the latter \\
\hline 5 & The former is obviously more important than the latter \\
\hline 7 & The former is strongly more important than the latter \\
\hline 9 & The former is extremely more important than the latter \\
\hline $2,4,6,8$ & The intermediate value of the above judgment \\
\hline Reciprocal & $\begin{array}{l}\text { If the ratio of importance between elements } \mathrm{I} \text { and } \mathrm{j} \text { is } \mathrm{m}_{i j} \text {, the ratio of importance } \\
\text { between elements } \mathrm{J} \text { and } \mathrm{I} \text { is } \mathrm{m}_{i j}=1 / \mathrm{m}_{j i}\end{array}$ \\
\hline
\end{tabular}

Table 3. The implication of importance assignment scale 
Table 4. Random consistency indicators

\begin{tabular}{c|c|c|c|c|c|c|c|c}
\hline Order of matrix & 1 & 2 & 3 & 4 & 5 & 6 & 7 & 8 \\
\hline R.I. & 0 & 0 & 0.52 & 0.89 & 1.12 & 1.26 & 1.36 & 1.41 \\
\hline Order of matrix & 9 & 10 & 11 & 12 & 13 & 14 & 15 & - \\
\hline R.I. & 1.46 & 1.49 & 1.52 & 1.54 & 1.56 & 1.58 & 1.59 & - \\
\hline
\end{tabular}

Finally, the weights of factors in each layer relative to the upper layer factors were calculated top-down layer by layer, and sorted according to the weight, and then subject to the consistency check according to Equation 4. If the value of C.R. ${ }^{(\mathrm{m}+1)}$ of the total elements in $(m+1)$ layer is less than 0.1 , then the total sorting is considered to be consistent, otherwise, it is not consistent.

$$
C . R^{(m+1)}=\frac{C^{\left(I^{(m+1)}\right.}}{\text { R.I. }^{(m+1)}}
$$

where:

$$
\begin{gathered}
C \cdot R_{\cdot j}^{(m+1)}=\left(C \cdot R_{\cdot 1}^{(m+1)}, C \cdot R_{\cdot 2}^{(m+1)}, \ldots, C . R_{\cdot n}^{(m+1)}\right) W^{m} \\
R . I_{\cdot j}^{(m+1)}=\left(R . I_{\cdot}^{(m+1)}, R \cdot I_{\cdot 2}^{(m+1)}, \ldots, R . I_{\cdot n}^{(m+1)}\right) W^{m}
\end{gathered}
$$

Based on the AHP and above steps, the weights of the high-energy-consuming enterprises' energy conservation, emission reduction, and circular economy development level can be calculated, analyzed and evaluated comprehensively. According to the above-mentioned energy-conservation emission-reduction economic comprehensive system and the AHP, the eco-economic development of energyconservation and emission-reduction of several high-energy-consuming industries had been evaluated, and it is found that the effects of energy-conservation and emissionreduction of such enterprises are obvious, which is conducive to the development of eco-economy.

\section{Conclusion}

Based on the theory of circular economy and the basic concept of sustainable development, combining with data research and analysis, this paper carried out researches on the energy conservation and emission reduction and eco-economic construction of high-energy-consuming industries. The main conclusions are as follows:

- The energy consumption data of the metallurgical industry in the past 7 years shows that the energy consumption and comparable energy consumption of per ton steel are decreasing year by year, indicating that technological reform, policy regulation, economic coordination and other countermeasures have exerted positive effects on reducing energy consumption and pollutant emission and improving economic benefits of the industries during the production process. 
- For the energy conservation and emission reduction of high-energy-consuming industries, this paper constructed an energy conservation and emission reduction eco-economic system based on circular economy, which gradually achieved energy conservation and emission reduction through policy, technology, organizational structures, resources, and other approaches, it promoted the upgrade of the industries, and combined with the policies and economic countermeasures, and implemented the energy conservation and emission reduction of the industries from two aspects of inside and outside.

- The energy conservation and emission reduction eco-economic system of highenergy-consuming industries based on circular economy is conductive to the improvement of the high energy consumption of the industries, and it laid a foundation for the eco-economic development of high-energy-consuming industries and the sustainable development of the society.

- This paper conducts a preliminary study on the energy reduction of highenergy-consuming industries from a macro perspective. However, at the micro level, it still requires more in-depth and systematic research on how the highenergy-consuming industries coordinate economic interests and social interests by organically combining them to effectively improve the level of ecological economic construction in energy conservation and emission reduction.

Acknowledgements. Qinghai Social Science Fund Project, Project number: 17001; Ministry of Education “Chunhui Plan” project, Project number: Z2017041.

\section{REFERENCES}

[1] Algaba, A., Fernández Sánchez, F., Merino, M., Rodríguez Luis, A. J. (2012): Comments on analysis and application of a novel three-dimensional energy-saving and emissionreduction dynamic evolution system. - Energy 40(1): 291-299.

[2] Cheng, C. T., Shen, J. J., Wu, X. Y., Chau, K. W. (2012): Operation challenges for fastgrowing China's hydropower systems and respondence to energy saving and emission reduction. - Renewable \& Sustainable Energy Reviews 16(5): 2386-2393.

[3] Cordova-Pizarro, D., Aguilar-Barajas, I., Romero, D., Rodriguez, C. A. (2019): Circular economy in the electronic products sector: material flow analysis and economic impact of cellphone e-waste in Mexico. - Sustainability 11(5): 1631.

[4] Danza, L., Belussi, L., Floreani, F., Meroni, I., Piccinini, A., Salamone, F. (2018). Application of model predictive control for the optimization of thermo-hygrometric comfort and energy consumption of buildings. - Instrumentation Mesure Métrologie 17(3): 375-391.

[5] Gallagher, J., Basu, B., Browne, M., Kenna, A., Mccormack, S., Pilla, F., Styles, D. (2017): Adapting stand-alone renewable energy technologies for the circular economy through eco-design and recycling. - Journal of Industrial Ecology 23(1): 133-140.

[6] Habib, M. A., Hasanuzzaman, M., Hosenuzzaman, M., Salman, A., Mehadi, M. R. (2016): Energy consumption, energy saving and emission reduction of a garment industrial building in Bangladesh. - Energy 112: 91-100.

[7] Hobson, K., Lynch, N. (2016): Diversifying and de-growing the circular economy: radical social transformation in a resource-scarce world. - Futures 82: 15-25.

[8] Jonas, M., Michael, J., Claudia, B. (2018): Transition of the Swiss Phosphorus System towards a circular economy-part 1: current state and historical developments. Sustainability 10(5): 1479. 
[9] Krishna, V. M. (2018): Emissions control and performance evaluation of spark ignition engine with oxy-hydrogen blending. - International Journal of Heat and Technology 36(1): 118-124.

[10] Lei, J. Y., Xie. J., Gan. D. Q. (2009): Optimization of distributed energy system and benefit analysis of energy saving and emission reduction. - Automation of Electric Power Systems 33(23): 29-36.

[11] Liao, G. C. (2011): A novel evolutionary algorithm for dynamic economic dispatch with energy saving and emission reduction in power system integrated wind power. - Energy 36(2): 1018-1029.

[12] Mostafaei, A., Mirrzaei, M., Ghazvini, M., Ahmadi, M. H., Lorenzini, G. (2019): Investigation of energy saving in building by using phase-change materials (PCM). Mathematical Modelling of Engineering Problems 6(1): 47-51.

[13] Murray, A., Skene, K., Haynes, K. (2017): The circular economy: an interdisciplinary exploration of the concept and application in a global context. - Journal of Business Ethics 140(3): 369-380.

[14] Peters, G. P., Weber, C. L., Guan, D., Hubacek, K. (2007): China's growing $\mathrm{CO}_{2}$ emissions - a race between increasing consumption and efficiency gains. - Environmental Science \& Technology 41(17): 5939-5944.

[15] Price, L., Levine, M. D., Zhou, N., Fridley, D., Aden, N., Lu, H., McNeil, M., Zheng, N., Qin, Y. N., Yowargana, P. (2011): Assessment of China's energy-saving and emissionreduction accomplishments and opportunities during the 11th five year plan. - Energy Policy 39(4): 2165-2178.

[16] Rigueiro-Rodríguez, A., Amador-García, A., Ferreiro-Domínguez, N., Muñoz, N., Santiago-Freijanes, J. J., Mosquera-Losada, M. R. (2018): Proposing policy changes for sewage sludge applications based on zinc within a circular economy perspective. - Land Use Policy S0264837718300425.

[17] Rudra, J. P., Chakraborty, M. (2017). Increase in lifetime by harvested energy and analysis of RC5 along with efficient energy consumption in WBAN. - Environmental and Earth Sciences Research Journal 4(2): 39-44.

[18] Tao, F., Zuo, Y., Xu, L. D., Lv, L., Zhang, L. (2014): Internet of things and BOM-based life cycle assessment of energy-saving and emission-reduction of products. - IEEE Transactions on Industrial Informatics 10(2): 1252-1261.

[19] Tiening, C., Jimei, Z. (2018): Bibliometric and review of the research on circular economy through the evolution of Chinese public policy. - Scientometrics 116(2): 10131037.

[20] Tomi, T., Schneider, D. R. (2017): Municipal solid waste system analysis through energy consumption and return approach. - Journal of Environmental Management 203: 973987.

[21] Trica, C. L., Banacu, C. S., Busu, M. (2019): Environmental factors and sustainability of the circular economy model at the European Union level. - Sustainability 11: 1114.

[22] Tu, J. Z., Ma, D. L. (2018): A spatial economics perspective on convergence research of carbon emissions performance in China. - International Journal of Heat and Technology: 36(3): 962-972. 